\title{
International Journal of Vaccines and Immunization
}

\section{Why Conduct Effective Vaccine Management (Evm) Assessment?}

\section{Stanley K Diamenu ${ }^{1 *}$, George Bosnu ${ }^{2}$, Francis Abotsi ${ }^{2}$, Kwame Amponsa-Achiano ${ }^{2}$, Fred Sarpong ${ }^{2}$, Frederick Dadzie ${ }^{2}$, Pamela Quaye ${ }^{2}$, Diana Baidoo ${ }^{2}$, Dan Osei ${ }^{3}$, Kofi Asemanyi- Mensah $^{4}$, Kofi Issah ${ }^{4}$, Daniel Yayeman ${ }^{5}$ and Souleymane Kone ${ }^{6}$}

${ }^{1}$ WHO country office for Ghana, Accra, Ghana

${ }^{2}$ National EPI Office, Ghana Health Service, Korle Bu, Accra, Ghana

${ }^{3}$ Ministry of health Accra, Ghana

${ }^{4}$ Regional Health Administration, Western and Brong Ahafo regions, Ghana

${ }^{5}$ UNICEF Country office, Accra, Ghana

${ }^{6}$ World Health Organization, HQ, Geneva, Switzerland

'Corresponding author: Stanley K Diamenu, WHO Country Office for Ghana, 29 Volta Street, Airport Residential Area, P.O. Box MB 142, Accra, Ghana, E-mail: diamenus@who.in
Received date: 7 Nov 2015; Accepted date: 26 Nov 2015; Published date: 1 December 2015.

Citation: Diamenu SK, Bosnu G, Abotsi F, AchianoAK, Sarpong F, et al. (2015) Why Conduct Effective Vaccine Management (Evm) Assessment? Int J Vaccine Immunizat 1(1): doi http://dx.doi.org/10.16966/24709948.104

Copyright: (C) 2015 Diamenu SK, et al. This is an open-access article distributed under the terms of the Creative Commons Attribution License, which permits unrestricted use, distribution, and reproduction in any medium, provided the original author and source are credited.

\begin{abstract}
Background: WHO and UNICEF supported Ghana to conduct Effective Vaccine Management (EVM) assessments in September 2010 and October 2014 respectively with the view to strengthening vaccine and logistics management for immunization at all levels in the country. In both assessments, temperature monitoring, which is a critical indicator for vaccine potency and immunization programme effectiveness, got very low scores of $50 \%$ (2010) and 67\% (2014) respectively at the national level and even lower at the regional level. The low scores of temperature monitoring at the national and regional levels in both assessments generated concern and interest for review of the results of the two assessments to determine some of the contributing factors considering Ghana's advancement in immunization with support of the Gavi Alliance and also with twelve antigens in the routine immunization programme.
\end{abstract}

Objective: The main objective of the review was to determine causes of the poor performance of the temperature monitoring and to devise strategies to improve on it.

Methods: Desk review of relevant documents including 2010 and 2014 EVM assessment reports, the report of the 2012 comprehensive EP Review and the status of implementation of recommendations of the 2010 EVM assessment and the 2012 EPI Review was conducted.

Results: The documents review revealed that the 2010 EVM assessment and the 2012 EPI Review recommended installation of continuous electronic temperature monitoring devices in the national and regional vaccine stores but it has not been implemented. The same recommendation has again been made from the 2014 EVM assessment.

Conclusions: There was no significant improvement in the scores of temperature monitoring between the 2010 (50\%) and 2014 (67\%) assessment because of the failure of the Immunization Programme to implement the recommendations of the previous assessment (2010) and the EPI Review (2012) which called for installation of the continuous electronic temperature monitoring devices in the national and regional vaccine stores. Not until the continuous electronic temperature monitoring devices are installed, the scores of temperature monitoring will forever remain low in any future assessment. The question is why use limited resources to conduct EVM assessment if the recommendations to address key challenges of the immunization programme are not to be implemented? Countries conducting EVM in future should make plans to implement the recommendations from the outcome. This is the only way there can be improvement in the immunization programme. Periodic EVM assessment is essential to keep the supply chain system at the required standard.

Keywords: Effective Vaccine Management (EVM); EPI; Temperature monitoring; Ghana

\section{Introduction}

Immunization in Ghana: Ghana is a tropical country situated on the west coast of Africa sharing common borders with neighbouring Togo to the East, Burkina Faso to the North, and Cote d'Ivoire to the West. There are 10 administrative regions, 216 districts and more than 3000 service delivery points providing immunization services through static and outreach points. The Government of Ghana launched the Expanded Programme on Immunization (EPI) in 1978 with six antigens, namely BCG, DPT, OPV and measles for the $<1$ year age children together with TT for pregnant women. With support from the Gavi Alliance since 2001, Ghana currently has twelve antigens in the routine immunization programme [1]. In addition there is also measles second dose for children at 18 months as presented in the country's immunization schedule in (Table 1). There is also tetanus-diphtheria (Td) for pregnant women as well as women in the child bearing age. The country plans to introduce two more vaccines; the inactivated polio vaccine (IPV) and the meningococcal A conjugate vaccine (MenAfrivac) into the routine programme by early $2016[2,3]$

Ghana adopted the reaching every district (RED) approach in 2003 and has been implementing it in all the districts. In addition to the routine immunization programme, the country also conducts supplemental immunization activities (SIA) to accelerate the reduction in the incidence of vaccine preventable diseases such as poliomyelitis (also known as polio), measles, yellow fever, meningitis, etc. Some of the achievements of the immunization programme in Ghana include (i) high routine immunization coverage as illustrated in (Table 2) (ii) a break in the transmission of wild poliovirus since November 2008, (iii) no deaths due to measles since 2003, (iv) maternal and neonatal tetanus elimination in 2011 by WHO assessment criteria, (v) reduction in severe diarrhea which is being monitored through sentinel site surveillance at two teaching

Copyright: $\odot 2015$ Diamenu SK, et al. This is an open-access article distributed under the terms of the Creative Commons Attribution License, which permits unrestricted use, distribution, and reproduction in any medium, provided the original author and source are credited. 


\begin{tabular}{|c|c|c|c|}
\hline & Vaccines & Doses & Route and Site of Injection \\
\hline \multirow{2}{*}{ At Birth } & BCG & $0.05 \mathrm{ml}$ & Intra-dermal, right upper arm \\
\hline & OPV0 & 2 drops & Oral \\
\hline \multirow{4}{*}{6 weeks } & DPT-HepB-Hib 1 & $0.5 \mathrm{ml}$ & $\begin{array}{l}\text { Intra-muscular, lateral aspect } \\
\text { of left thigh }\end{array}$ \\
\hline & OPV 1 & 2 drops & Oral \\
\hline & Pneumo 1 & $0.5 \mathrm{ml}$ & $\begin{array}{l}\text { Intra-muscular, lateral aspect } \\
\text { of right thigh }\end{array}$ \\
\hline & Rota 1 & $1.5 \mathrm{ml}$ vial & Oral \\
\hline \multirow{4}{*}{10 weeks } & DPT-HepB-Hib 2 & $0.5 \mathrm{ml}$ & $\begin{array}{l}\text { Intra-muscular, lateral aspect } \\
\text { of left thigh }\end{array}$ \\
\hline & OPV 2 & 2 drops & Oral \\
\hline & Pneumo 2 & $0.5 \mathrm{ml}$ & $\begin{array}{l}\text { Intra-muscular, lateral aspect } \\
\text { of right thigh }\end{array}$ \\
\hline & Rota 2 & $1.5 \mathrm{ml}$ vial & Oral \\
\hline \multirow{3}{*}{14 weeks } & DPT-HepB-Hib 3 & $0.5 \mathrm{ml}$ & $\begin{array}{l}\text { Intra-muscular, lateral aspect } \\
\text { of left thigh }\end{array}$ \\
\hline & OPV 3 & 2 drops & Oral \\
\hline & Pneumo 3 & $0.5 \mathrm{ml}$ & $\begin{array}{l}\text { Intra-muscular, lateral aspect } \\
\text { of right thigh }\end{array}$ \\
\hline nths & Vitamin A & $100,000 \mathrm{IU}$ & Oral \\
\hline \multirow{2}{*}{9 months } & Measles-Rubella & $0.5 \mathrm{ml}$ & $\begin{array}{l}\text { Subcutaneous, left upper } \\
\text { arm }\end{array}$ \\
\hline & Yellow Fever & $0.5 \mathrm{ml}$ & $\begin{array}{l}\text { Subcutaneous, right upper } \\
\text { arm }\end{array}$ \\
\hline 12 months & Vitamin A & $200,000 \mathrm{IU}$ & Oral \\
\hline \multirow{2}{*}{18 months } & Measles & $0.5 \mathrm{ml}$ & $\begin{array}{l}\text { Subcutaneous, left upper } \\
\text { arm }\end{array}$ \\
\hline & Vitamin A & $200,000 \mathrm{IU}$ & Oral \\
\hline \multicolumn{4}{|c|}{$\begin{array}{l}\text { After } 18 \text { months Vitamin A is given for every } 6 \text { months till chilf is } 5 \text { years } \\
\text { old }\end{array}$} \\
\hline \multicolumn{4}{|c|}{$\begin{array}{l}18 \text { months- Give Long lasting Insecticide Treated Nets (LLINs) to the } \\
\text { child }\end{array}$} \\
\hline
\end{tabular}

Table 1: Immunization Schedule in Ghana

\begin{tabular}{|c|c|c|c|c|}
\hline \multicolumn{5}{|c|}{ Year } \\
\hline & 2011 & 2012 & 2013 & 2014 \\
\hline BCG & 105 & 104 & 98 & 103 \\
\hline Penta 1 & 90 & 92 & 89 & 93 \\
\hline Penta 2 & 86 & 87 & 85 & 89 \\
\hline Penta 3 & 87 & 88 & 86 & 90 \\
\hline OPV1 & 89 & 91 & 88 & 93 \\
\hline OPV2 & 86 & 87 & 86 & 90 \\
\hline OPV3 & 87 & 87 & 86 & 90 \\
\hline PCV-13-1 & \multirow{5}{*}{$\begin{array}{l}\text { Rota and PCV13 Not } \\
\text { Introduced }\end{array}$} & 64 & 88 & 93 \\
\hline PCV-13-2 & & 51 & 84 & 90 \\
\hline PCV-13-3 & & 40 & 84 & 91 \\
\hline Rota-1 & & 59 & 87 & 92 \\
\hline Rota-2 & & 47 & 83 & 89 \\
\hline Measles 1 & 88 & 89 & 84 & 88 \\
\hline Measles 2 & NA & 51 & 51 & 64 \\
\hline YF & 87 & 88 & 84 & 87 \\
\hline TT2+ & 76 & 74 & 71 & 62 \\
\hline
\end{tabular}

Table 2: National Immunization coverage from 2011-2014 hospitals, and (vi) significant reduction in rubella morbidity following the introduction of the measles-rubella vaccine in 2013 [4].

In spite of the achievements of the immunization programme, challenges still exist that inhibit the total success of the programme. Some of these challenges are (i) Inadequate and irregular funding for routine immunization activities (ii) poor access to immunization service delivery in island communities in the districts located in the Volta Lake Basin (iii) increasing number of unimmunized children mostly in the urban and peri-urban centres. About $12 \%$ of the annual immunization target is often not reached with the third dose of the pentavalent vaccine every year (iv) poor community involvement and participation in the immunization decision-making process, and (v) data quality issues emanating from inaccurate population figures and inadequate knowledge and skills in data management.

\section{Functional Cold chain facility by type in Ghana}

The EPI vaccine supply chain in Ghana is composed of a national cold store, 10 regional cold stores in each of the regional capitals, 216 districts cold stores and more than 3000 sub-district stores each of them distributing vaccines to peripheral health facilities where immunization services are provided.. The national and regional cold stores have walkin-cold rooms (WICR). Type of cold chain facility in Ghana is presented in (Table 3) [5].

Ghana adopted the use of auto disposable (AD) syringes for all vaccination injections since 2002. In addition all the EPI vaccines are procured from international manufacturers and bundled with safe injection equipment through UNICEF. There is no local production of vaccines and safe injection equipment. (Table 4 ) below is the total vaccine projection from 2015-2019 for the immunization programme which has been extracted from the country's EPI 5-year multi-year strategic plan [6].

\section{Effective Vaccine Management (EVM) Assessment in Ghana}

Effective Vaccine Management (EVM) assessment is a comprehensive evaluation of the supply chain system of the Immunization programme to identify the strengths and weakness of the system at all levels to enhance the development of an effective roadmap for improvement.

EVM assessment provides guideline for close monitoring of the cold chain which is mandatory for liquid vaccines which are highly sensitive to freezing and overheating [7]. It's scope and focus are based on the following nine global criteria each of which is validated against records kept over a recent 12 month period during every assessment. (i) Preshipment and arrival procedures to ensure that every shipment from the vaccine manufacturer reaches the receiving store in satisfactory condition and with correct paperwork; (ii) Temperature monitoring to ensure all vaccines and diluents are stored and distributed within WHOrecommended temperature ranges; (iii) Cold storage, dry storage and transport capacity is sufficient to accommodate all vaccines and supplies needed for the programme; (iv) Buildings, cold chain equipment and transport systems are appropriate to enable the vaccine and consumables supply chain to function effectively; (v) Maintenance of buildings, cold chain equipment and vehicles is satisfactory; (vi) Stock management systems and procedures are effective; (vii) Distribution between each level in the supply chain is effective; (viii) Appropriate vaccine management policies are adopted and implemented; (ix) Information systems and supportive management functions are satisfactory. The EVM process is first and foremost about embedding good storage and distribution practices. It has been designed to be used both as an assessment tool for the systematic analysis of strengths and weaknesses across the supply chain and also as a supervisory aid to monitor and support the long-term progress of individual facilities. EVM is expected every 3 years especially 


\begin{tabular}{|c|c|c|c|c|c|c|}
\hline $\begin{array}{c}\text { Store level } \\
\text { National/Region }\end{array}$ & Districts & WICR & $\begin{array}{l}\text { TCW } \\
3000\end{array}$ & $\begin{array}{l}\text { TCW } \\
2000\end{array}$ & $\begin{array}{l}\text { Other } \\
\text { fridges }\end{array}$ & Total \\
\hline National & & $160 \mathrm{~m}^{3}$ & NA & NA & NA & NA \\
\hline Ashanti & 30 & $40 \mathrm{~m}^{3}$ & 9 & 21 & 262 & 292 \\
\hline Brong Ahafo & 27 & $40 \mathrm{~m}^{3}$ & 18 & 19 & 241 & 278 \\
\hline Central & 20 & $40 \mathrm{~m}^{3}$ & 16 & 14 & 213 & 243 \\
\hline Eastern & 26 & $30 \mathrm{~m}^{3}$ & 25 & 26 & 296 & 347 \\
\hline G Accra & 16 & $80 \mathrm{~m}^{3}$ & 11 & 19 & 131 & 161 \\
\hline Northern & 26 & $80 \mathrm{~m}^{3}$ & 15 & 20 & 242 & 257 \\
\hline Upper East & 13 & $30 \mathrm{~m}^{3}$ & 11 & 10 & 143 & 164 \\
\hline Upper West. & 11 & $30 \mathrm{~m}^{3}$ & 8 & 7 & 145 & 160 \\
\hline Volta. & 25 & $30 \mathrm{~m}^{3}$ & 16 & 18 & 266 & 300 \\
\hline Western. & 22 & $30 \mathrm{~m}^{3}$ & 14 & 21 & 241 & 276 \\
\hline Total & 216 & & 143 & 175 & 1939 & 2478 \\
\hline
\end{tabular}

Table 3: Functional Cold Chain inventory in Ghana

\begin{tabular}{|c|c|c|c|c|c|c|c|c|c|}
\hline $\begin{array}{l}\text { Level of } \\
\text { Store }\end{array}$ & E1 & E2 & E3 & E4 & E5 & E6 & E7 & E8 & E9 \\
\hline $\begin{array}{l}\text { PR-National } \\
\text { Store }\end{array}$ & $94 \%$ & $67 \%$ & $81 \%$ & $92 \%$ & $100 \%$ & $88 \%$ & $87 \%$ & $98 \%$ & $81 \%$ \\
\hline $\begin{array}{l}\text { SN-Regional } \\
\text { Store }\end{array}$ & \multirow{3}{*}{ NA } & $61 \%$ & $90 \%$ & $83 \%$ & $79 \%$ & $83 \%$ & $68 \%$ & $94 \%$ & $82 \%$ \\
\hline $\begin{array}{l}\text { LD-District } \\
\text { Store }\end{array}$ & & $74 \%$ & $84 \%$ & $87 \%$ & $62 \%$ & $73 \%$ & $79 \%$ & $91 \%$ & $67 \%$ \\
\hline $\begin{array}{l}\text { SP-Service } \\
\text { Point }\end{array}$ & & $71 \%$ & $77 \%$ & $82 \%$ & $59 \%$ & $57 \%$ & $92 \%$ & $81 \%$ & $60 \%$ \\
\hline
\end{tabular}

Table 4: Total vaccine projections in doses fro 2015-2019

in countries introducing new and multiple vaccines to address emerging challenges

EVM assessment was first conducted in Ghana in May 2001 at the inception of Gavi Alliance support for Immunization system strengthening in the country. It was a trial effort and not enough data was generated. As many new vaccines were introduced, it became necessary for regular and intensive assessment to be conducted to strengthen the system. The last two assessments were supported by WHO and UNICEF in September 2010 and October 2014 respectively. The main objective of each assessment has been to generate information that would enhance improvement in vaccine and logistics management in the country's immunization programme. Specific objectives included (i) building and strengthening national capacity for immunization programme assessment, (ii) identifying training needs for staff and equipment replacement needs at all levels (iii) using the findings to develop training programme and equipment replacement plans for immunization at all levels.

In each assessment, district and facility stores were randomly selected using the WHO standard effective vaccine management (EVM) assessment tool [8]. 43 and 69 facilities were assessed in the September 2010 and October 2014 respectively. In each assessment, Data was collected through site observation, review of relevant documents and interview of staff at all levels using questionnaire on the 9 Global EVM criteria described above. National and regional stores were also included in each assessment. The result of the 2014 assessment for all levels is summarized in (Table 5):

The scores of major indicators such as temperature monitoring, storage capacity, stock management, vaccine management and information management and supportive functions fell below the standard score of $80 \%$. The poorest performing score was for temperature monitoring at all

levels. It recorded $67 \%$ at national level and $61 \%$ at the regional level. The district and health facility stores rather scored $74 \%$ and $71 \%$ respectively above the national and regional stores.

Key challenges identified affecting vaccine management from the assessment in the country are: (i) Inadequate training (ii) Lack of continuous temperature monitoring devices (iii) Knowledge gaps in vaccine management, (shake test, icepack conditioning, stock management) (iv) Irregular supportive supervision at all levels (v) Lack of sustainable maintenance system for building, equipment and transport. Major recommendations include - training at all levels, expansion of storage capacity and intensification of supportive supervision [9].

\section{Rationale for Review of 2010 and 2014 EVM assessment results}

The introduction of measles second dose, pneumococcal conjugate vaccine (PCV 13) and rotavirus vaccine in 2012 and subsequent introduction of measles-rubella vaccine in 2013 into the routine immunization programme have brought massive upgrading of the cold chain system in the country. WICRs were procured and installed in all regions together with other cold chain facilities for the district and health facility stores to maintain standard temperature required for the vaccines and other logistics (Table 3). Store managers were regularly trained at all levels to update their knowledge in correct temperature for storing vaccines and how to look after vaccines. It was therefore surprising that the 2014 EVM assessment showed very low scores of $67 \%$ (national) and $61 \%$ (regional) $[9,10]$ for temperature monitoring as compared to other indicators presented in (Table 6).

The low scores of temperature monitoring at the national and regional levels in both assessments generated concern and interest for review of the results of the two assessments to determine some of the contributing factors considering Ghana's advancement in immunization with support of the Gavi Alliance and also with twelve antigens in the routine immunization programme.

\section{Objective}

The main objective of the review was to determine causes of the poor performance of the temperature monitoring at the national and regional levels and to devise strategies to improve on it.

\section{Methods}

Desk review of relevant documents including (i) 2010 and 2014 EVM assessment reports, (ii) the report of the 2012 comprehensive EPI Review and (iii) the status of implementation of recommendations of the 2010 EVM assessment and the 2012 EPI Review was conducted [11]. No interviews were conducted with any immunization programme management staff. That may be conducted later if a more elaborate study on the issue is required. The review concentrated only on national and regional level performance. It did not extend to the district and facility performance. This may also the considered in future review if necessary.

\section{Results}

The major revelation from the review was that both the 2010 EVM assessment and the 2012 comprehensive EPI Review recommended the installation of continuous electronic temperature monitoring devices in the national and regional vaccine stores but it has not been implemented. This has affected the temperature recordings in the national and regional stores. The same recommendation has again been made from the 2014 EVM assessment.

\section{Discussion}

Immunization programs are among the most effective public health strategies worldwide. Systematic and effective immunization programmes 


\begin{tabular}{|c|c|c|c|c|c|c|c|}
\hline Vaccines & Type & $\mathbf{2 0 1 5}$ & $\mathbf{2 0 1 6}$ & $\mathbf{2 0 1 7}$ & $\mathbf{2 0 1 8}$ & $\mathbf{2 0 1 9}$ \\
\hline BCG & Lyophilized & $2,250,100$ & $2,306,400$ & $2,364,000$ & $2,423,100$ & $2,483,700$ & $11,827,300$ \\
\hline tOPV & Liquid & $5,023,400$ & $1,248,300$ & - & - & - & $6,271,700$ \\
\hline bOPV1+3 & Liquid & - & $6,397,200$ & $5,277,700$ & $5,409,600$ & $1,344,200$ & $18,428,700$ \\
\hline IPV & Liquid & 675,100 & $2,411,200$ & $2,127,600$ & $2,180,800$ & $2,235,400$ & $9,630,100$ \\
\hline DTP-HepB-Hib & Liquid & $3,727,500$ & $3,820,600$ & $3,968,500$ & $4,110,800$ & $4,202,900$ & $19,830,300$ \\
\hline PCV-13 & Liquid & $3,138,900$ & $3,217,400$ & $3,341,900$ & $3,461,800$ & $3,539,300$ & $16,699,300$ \\
\hline Rota-liq & Liquid & $2,092,600$ & $2,114,900$ & $2,227,900$ & $2,307,900$ & $2,359,500$ & $11,132,800$ \\
\hline Measles & Lyophilized & 855,100 & $1,148,700$ & $1,178,800$ & $1,235,200$ & $1,317,100$ & $5,734,900$ \\
\hline MR & Lyophilized & $1,339,600$ & $1,373,100$ & $1,426,000$ & $1,457,900$ & $1,494,400$ & $7,091,000$ \\
\hline YF & Lyophilized & $1,339,600$ & $1,373,100$ & $1,426,000$ & $1,457,900$ & $1,494,400$ & $7,091,000$ \\
\hline Td & Liquid & $2,220,100$ & $2,275,600$ & $2,371,700$ & $2,423,100$ & $2,524,900$ & $11,815,400$ \\
\hline
\end{tabular}

Table 5: Summary result of 2014 EVM assessment for all levels

\begin{tabular}{|l|c|c|c|c|c|}
\hline \multicolumn{1}{|c|}{ Criteria } & $\begin{array}{c}\text { Standard } \\
\text { score }\end{array}$ & \multicolumn{2}{c|}{ National Store } & \multicolumn{3}{c|}{ Regional Store } \\
\hline & & $\mathbf{2 0 1 0}$ & $\mathbf{2 0 1 4}$ & $\mathbf{2 0 1 0}$ & $\mathbf{2 0 1 4}$ \\
\hline E1: Arrival procedures & 0.8 & 0.95 & 0.94 & \multicolumn{2}{c|}{ NA } \\
\hline E2:Temp monitoring & 0.8 & 0.5 & 0.67 & 0.69 & 0.61 \\
\hline E3:Storage and transport & 0.8 & 0.93 & 0.81 & 0.6 & 0.9 \\
\hline E4:Buildings, equip etc & 0.8 & 0.78 & 0.92 & 0.75 & 0.83 \\
\hline E5: Maintenance & 0.8 & 0.62 & 1 & 0.58 & 0.79 \\
\hline E6: Stock mgt & 0.8 & 0.73 & 0.88 & 0.69 & 0.83 \\
\hline E7: Distribution & 0.8 & 0.75 & 0.87 & 0.75 & 0.68 \\
\hline E8:Vaccine mgt & 0.8 & 0.78 & 0.96 & 0.78 & 0.94 \\
\hline E9:Mgt Info System & 0.8 & 0.48 & 0.81 & 0.66 & 0.82 \\
\hline
\end{tabular}

Table 6: Summary of EVMA results for 2010 and 2014 - Ghana

mostly depend on the correct maintenance and manipulation of the vaccines to be used, i.e. perfect maintenance of the cold chain [12].

In 1978 when Ghana launched EPI, there were only six antigens (BCG, DPT, OPV and measles) for the $<1$ year age together with TT for pregnant women. Today, there are twelve antigens with plans to add two more new vaccines in early 2016 . Vaccines are a key contributor to public health, especially in developing countries [13]. As the immunization programme expands, adequate vaccine storage is essential to assure the vaccines' effectiveness and safety [14].The revelation of very low scores for temperature monitoring in the 2010 and 2014 assessments at the national and regional levels has implication for the credibility of the stores because of the volume of vaccine kept at these levels. Vaccines are highly sensitive to freezing and overheating and as such, good temperature monitoring is very critical to ensure potency and safety. When a vaccine is damaged by freezing, the potency lost can never be restored. The damage is permanent. Freeze-damaged vaccines have lower immunogenicity and are more likely to cause local reactions, such as sterile abscesses [15].

Vaccines are also very expensive and once potency is lost, it can never be restored and the vaccine would become useless and anyone who receives vaccine with decreased potency caused by improper storage conditions may not be fully protected against the vaccine-preventable disease [16-18].

In addition to maintaining the cold chain system, store managers need regular orientation and supervision. Vaccines are heat-labile medications,

and to guarantee their immunogenicity and safeguarding effectiveness as part of immunization programs, it is absolutely essential that the "Cold Chain" go unbroken. Fundamental is regular orientation of the personnel responsible for the vaccines, who must know the stability characteristics of each preparation so as to prevent handling errors $[19,20]$

\section{Conclusions}

There was no significant improvement in the scores of temperature monitoring between the 2010 (50\%) and 2014 (67\%) assessment because of the failure of the Immunization Programme to implement the recommendations of the previous assessment (2010) and the EPI Review (2012) which called for installation of the continuous electronic temperature monitoring devices in the national and regional vaccine stores. A plan for full implementation of recommendations of each EVM assessment is as equally important the as conduct of the assessment itself. Why use limited resources to conduct EVM assessment if the recommendations to address key challenges of the immunization programme are not to be implemented? This is a lesson for countries planning to conduct EVM assessment. Periodic EVM assessment is essential to keep the supply chain system at the required standard.

\section{Competing interest - None declared}

\section{Authors' contributions}

SKD - WHO Country office for Ghana technical advice, funding and drafting of manuscript

GB, FA, KAA, FS, FD, PQ, DB - National EPI Programme

DO - Ministry of Health

KAM, KI - Regional level supervision DY-UNICEF country office, Ghana support

\section{SK - WHO external technical support}

\section{Acknowledgement}

Authors are grateful to all the health staff from the Ministry of health, Ghana health service and other Divisions and the regions who participated in the data collection exercise.

\section{References}

1. Expanded Programme on Immunization (Ghana) Measles-Rubella Elimination Strategic Plan (2015-2020) February 2015. 
2. Ministry of Health/Ghana Health Service (2014) Plan for Inactivated Polio Vaccine Introduction into Routine Immunization in Ghana.

3. Ministry of Health/Ghana Health service, Plan for Meningococcal A (Men A) Vaccine Introduction into Routine in Ghana.

4. Ministry of Health/Ghana Health Service (2014) Expanded programme on immunization, Report on post introduction evaluation of MCV2, PCV and Rotavirus vaccines in Ghana.

5. Expanded programme on Immunization (2014) National Cold chain Inventory Report.

6. Government of Ghana Comprehensive multi-year plan for immunizations (2015 - 2019) A Plan to reach every district to every child

7. World Health Organization (2014) Effective Vaccine Management (EVM) assessment Tool, Version v1.0.9.

8. World Health Organization (May 2010) The EVM site selection process and user guide for the EVM site selection tool. Version v1.1-beta.

9. Expanded Programme on Immunization (Oct 2014) Ghana EVM assessment Report.

10. Expanded Programme on Immunization (October 2010) Ghana EVM assessment Report.

11. Adelaide Damete-Yeboa Final Report on Volunteer Service EPI-Who country Office, Ghana 01 November 2012 - 31 January 2013.

12. Ortega Molina P1, Astasio Arbiza P, Albaladejo Vicente R, Arrazola Martínez P, Villanueva Orbáiz R, et al. (2007) Cold chain maintenance in vaccines: a systematic review Gac Sanit 21: 343-8.
13. Peny JM1, Gleizes O, Covilard JP (2005) Financial requirements of immunisation programmes in developing countries: a 2004-2014 perspective. Vaccine 23: 4610-8.

14. Thielmann A, Viehmann A, Weltermann BM (2015) Effectiveness of a web-based education program to improve vaccine storage conditions in primary care (Keep Cool): study protocol for a randomized controlled trial. Trials 16:301.

15. Kartoglu U, Özgüler NK, Wolfson LJ, Kurzatkowski W (2010) Validation of the shake test for detecting freeze damage to adsorbed vaccines. Bulletin of the World Health Organization 88:624-631.

16. CDC - Vaccine storage and handling Toolkit National centre for immunization and Respiratory Diseases

17. Bell KN, Hogue CJ, Manning C, Kendal AP (2001) Risk factors for improper vaccine storage and handling in private provider offices. Pediatrics 107: E100.

18. Schlumberger M, Mireux F, Tchang SG, Mboutbogol D, Cheikh DO, et al. (2011) Computerized temperature monitoring of the vaccine cold chain in a tropical climate, Chad. Med Trop (Mars) 71: 264-6.

19. Ortega Molina P1, Astasio Arbiza P, Albaladejo Vicente R, Gómez Rábago ML, de Juanes Pardo JR, et al. (2002) Vaccine storage cold chain at primary care centers in one area of Madrid: keeping the chain intact and degree of knowledge. Rev Esp Salud Publica 76: 333-46.

20. Barber-Hueso C1, Rodríguez-Sánchez O, Cervera-Pérez I, Peiró $S$ (2009) The vaccine cold chain in a Valencian health department (Spain). Gac Sanit 23: 139-43. 